\title{
Prenatal Diagnosis of Type 1c Choledochal Cysts in 1 Month Old Baby
}

\author{
Ida Ayu Agung Wijayanti ${ }^{1}$, Ni Nyoman Metriani Nesa ${ }^{1}{ }^{*}$, I Gusti Ngurah Sanjaya Putra ${ }^{1}$, \\ I Putu Gede Karyana ${ }^{1}$, Kadek Deddy Ariyanta ${ }^{2}$, I Made Dharmajaya ${ }^{2}$, Ni Made Mahastuti ${ }^{3}$ \\ ${ }^{1}$ Department of Child Health, Faculty of Medicine, Udayana University/Sanglah Hospital, Denpasar, Indonesia \\ ${ }^{2}$ Department of Surgery, Faculty of Medicine, Udayana University/Sanglah Hospital, Denpasar, Indonesia \\ ${ }^{3}$ Department of Anatomical Pathology, Faculty of Medicine, Udayana University/Sanglah Hospital, Denpasar, Indonesia
}

\section{Email address:}

dayuagungwijayanti@gmail.com (I. A. A. Wijayanti), metriani_nesa@yahoo.co.id (Ni N. M. Nesa)

${ }^{*}$ Corresponding author

\section{To cite this article:}

Ida Ayu Agung Wijayanti, Ni Nyoman Metriani Nesa, I Gusti Ngurah Sanjaya Putra, I Putu Gede Karyana, Kadek Deddy Ariyanta, I Made Dharmajaya, Ni Made Mahastuti. Prenatal Diagnosis of Type 1c Choledochal Cysts in 1 Month Old Baby. American Journal of Pediatrics. Vol. 7, No. 2, 2021, pp. 49-52. doi: 10.11648/j.ajp.20210702.12

Received: March 10, 2021; Accepted: March 30, 2021; Published: April 13, 2021

\begin{abstract}
Choledochal cysts (CCs) are congenital dilatations of extrahepatic and/or intrahepatic bile ducts. It is a rare biliary entity, in the Asian population, the incidence can be as high as 1:1000 live. We reported case of One-month old baby girl with yellowish skin and acholic stool the baby has been suspected with anechoic abdominal mass at 17 weeks of gestational age using fetal ultrasound. From physical examination, jaundice was seen on the sclera and all over the body. The bowel sound was normal, without distention, without palpable liver nor spleen. The mass was not palpable either. Aspartate transaminase serum (AST), alanine aminotransferase serum (ALT), gamma glutamyl tranferase (GGT), bilirubin level was increased. Ultrasound was performed and revealed extrahepatic dilation to form a saccus in the proximal CBD, according to the picture of type 1 choledocal cyst. The surgeon performed cyst excision and hepatoduodenostomy procedure and found choledochal cyst. Histopathologic examination from cyst confirmed the choledochal cyst. The patient was discharged in good condition. We conclude that Type I choledochal cysts can be identified prenatally during a detailed fetal sonogram. The newborn should be investigated to confirm the diagnosis and undergo cyst excision promptly to reduce the potential for complications.
\end{abstract}

Keywords: Choledochal Cyst, Prenatal Diagnosis, Treatment, Surgery

\section{Introduction}

Choledochal cysts (CCs) are congenital dilatations of extrahepatic and/or intrahepatic bile ducts. It is a rather rare condition whereby biliary entity with an estimated incidence of $1: 100,000$ up to $1: 150,000$ live births in Western countries. However, for Asian population, the incidence was found to be as high as 1:1000 live $[1,2]$. Female children are higher risk for the disease with a nearly $4: 1$ female preponderance. Nearly, $80 \%$ of CCs are diagnosed in early infancy [3, 4]. Choledochal cysts (CCs) are first classified in 1959 by Alanso-Lej and colleagues. The original classification identified four types of biliary cysts (types I- IV). In 1977, Todani and colleagues revised the classification and added a fifth category of $\mathrm{CC}$, type V biliary cysts or Carol disease $[5,6]$. Prenatal ultrasonography is now being routinely performed worldwide and the detection of choledochal cysts have been reported in fetus as early as 15-16 weeks of gestation. For those who had this condition suspected antenatally, diagnosis is further confirmed after birth by post-natal ultrasound and magnetic resonance cholangiopancreatography [7]. We report a case of choledochal cyst by prenatally diagnosis in one month old baby. The objective of this case report was to present the clinical manifestation diagnosis and management choledochal cyst.

\section{Case Illustration}

One-month old baby girl brought to hospital with yellowish skin. The baby has been suspected with anechoic abdominal mass on 17 weeks of gestational age on fetal ultrasound 
examination. The mass was discovered accidentally when the mother had a routine check-up with the obstetrician. During pregnancy, the mother went to the obstetrician regularly to observe the development of cysts in the fetus. On 38 weeks of gestational age, the cyst appeared on the bile duct with diameter $2.29 \mathrm{~cm} \times 2.03 \mathrm{~cm}$ (figure 1). During pregnancy the fetus developed well, the mother had no notable complaints nor symptoms. The mother did not have congenital diseases, she did not take other medication regularly and has never been ill during pregnancy.

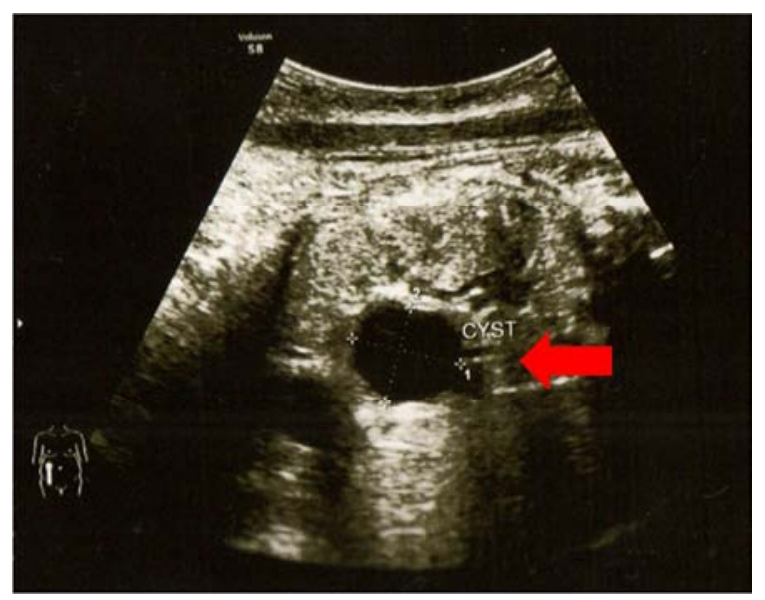

Figure 1. Bile duct cyst at 38 weak of gestational age.

The baby was the fourth child born to a mother aged 38 years old, she was born by section cesarean with a birth weight of 3170 grams at term. Yellowish skin was observed when the baby was 1 week old, it was accompanied with acholic stool and light yellow urine. There were no abdominal distention nor palpable mass. Physical examination revealed jaundice on the sclera and all over the body. The bowel sound was normal, there were no distention, no signs of peritonitis, the palpable liver, spleen, nor mass were not found. There was no ascites nor marks cirrhosis of the liver.

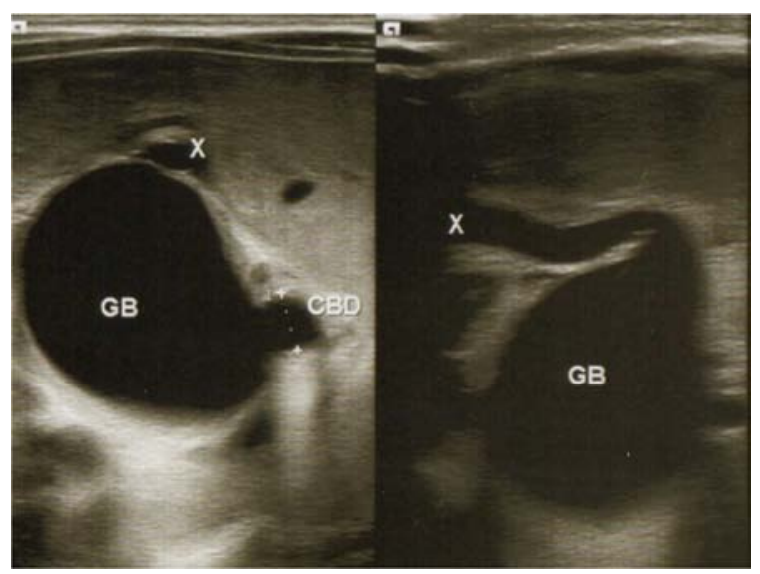

Figure 2. Choledocus cyst at 21 days of age.

Ultrasound was performed on the baby at 21 days of age. The results were extrahepatic dilation to form a saccus in the proximal CBD, according to the picture of type 1 choledocal cyst (Figure 2). Complete Blood Count was normal with haemoglobin ( $\mathrm{Hb}) 16.8 \mathrm{~g} / \mathrm{dL}$, haematocrit (Ht) 49,39\%, leukocytes $11.200 \mathrm{~mm}^{3}$ and thrombocytes $325.000 \mathrm{~mm}^{3}$. Liver function test showed increase of total bilirubin at $13.80 \mathrm{mg} / \mathrm{dL}$ with direct bilirubin 6.80 , indirect bilirubin $7 \mathrm{mg} / \mathrm{dl} . \mathrm{mg} / \mathrm{dL}$, serum aspartate transaminase (AST) 63,8 U/L, alkaline phosphates (ALP) $245 \mathrm{mg} / \mathrm{dL}$ and gamma glutamyltranferase (GGT) 323 U/L. Alanine aminotransferase (ALT) 19,50 U/L was normal. Coagulation profile, showed international normalized ratio (INR) 1.09 with partial thromboplastin time (PPT) was 15.3, activated partial thromboplastin time (APTT) was 43,2. Renal function test revealed BUN $5.7 \mathrm{mg} / \mathrm{dL}$ and creatinine serum $0.42 \mathrm{mg} / \mathrm{dL}$. Stool sample shown was acholic. Based on clinical manifestation, and imaging findings, we assessed the patient with type I choledochal cysts.

Treatment plan were cyst removal surgery and hepatoduodenostomy. Initially the patient underwent laparoscopy, but the posterior wall of the distal cyst was sticking to the duodenum, so the operation was continued with a laparotomy and cyst excision with biopsy. After the surgery was performed, the choledochal cyst with size $5 \times 2,5 \times 0,5 \mathrm{~cm}$ as a biopsy sample and sent to Anatomy Pathologic department for examination (Figure 3).

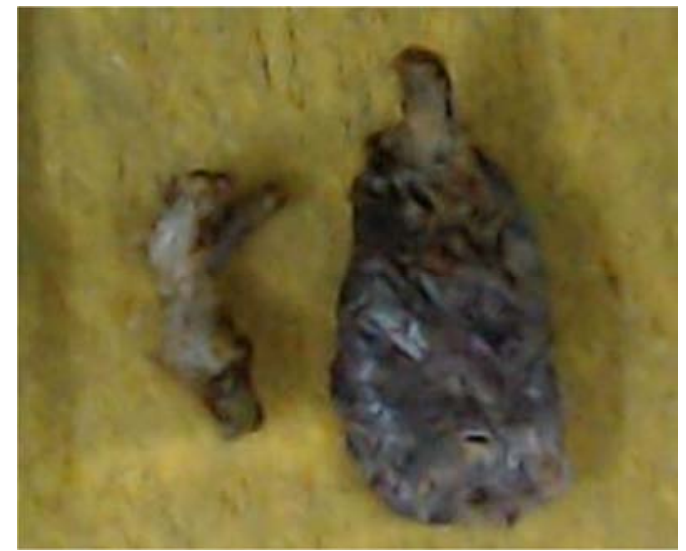

Figure 3. Macroscopic Sample Of Choledocal Cysts.

Pathologic examination from biopsy sample confirmed diagnosis of type I choledochal cyst (figure 4).

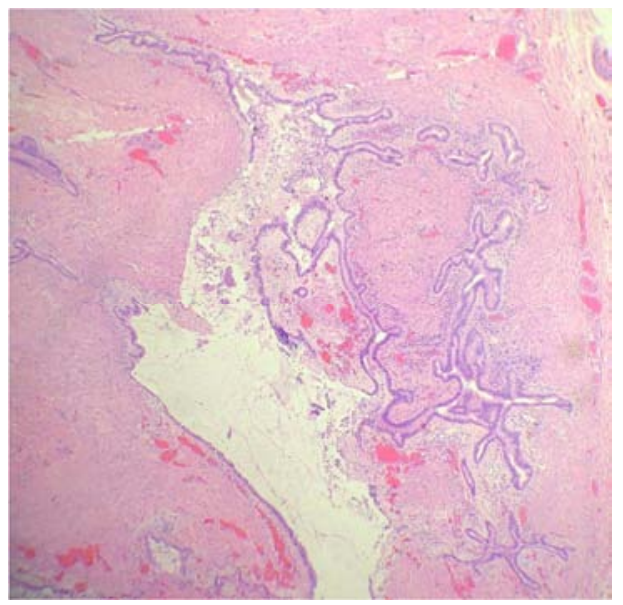

Figure 4. Histopathologic results from choledocal cyst. 
No complication was observed post-surgical procedure and patient was discharged in a good condition after the seventh day.

\section{Discussion}

Choledochal cysts are rare anomalies that appear as cystic or fusiform dilatations of the extra or intrahepatic biliary tree. The incidence of CCs is 1:100-150,000 live births in Western countries. In the Asian population, the incidence can be as high as 1:1000 live. Choledochal cysts are more commonly found in female children [1-4]. Symptoms depend on the age at presentation. In infant form, symptoms such as obstructive jaundice, clay colored stools, and hepatomegaly proved to be difficult to be distinguished from biliary atresia. There are three main symptoms in the classical clinical triad: recurrent jaundice found in $69-75 \%$ of cases, right upper quadrant pain found in $47-60 \%$ of cases, and right upper quadrant mass found in $47-80 \%$ of cases, but the classic triad only presents in $10 \%$ of cases (6-25\%) [6] Obstructive jaundice is the main presentation symptom in children $[4,8$, 14] Patient came with symptoms of jaundice and acholic stool. There was no abdominal pain nor palpable mass found. These complaints were reportedly present since the patient was one week old.

The exact etiology remains incompletely understood. There are two main theories widely accepted in present days;; (1) reflux of trypsin and other pancreatic enzymes to the bile ducts due to an Anomalous pancreaticobiliary ductal union (APBDU); (2) obstruction of distal common bile duct (CBD) [6]. The etiology in this patient still unknown, there was no reported history of illness during pregnancy period.

According to previous studies, there are five type of choledochal cysts, among which, Type I cysts are the most frequent choledochal cysts. The classification of choledochal cysts are as follows: type IA: cystic dilatation of the extrahepatic duct; type IB: focal segmental dilatation of the extrahepatic duct; type IC: fusiform dilatation of the entire extrahepatic bile duct and common bile duct; type II: simple diverticulum of the common bile duct; type III: cyst/choledochocele distal intramural dilation of the common bile duct; type IVA: combined intrahepatic and extrahepatic bile duct dilatation; type IVB: multiple extrahepatic bile duct dilations; type V: multiple intrathepatic bile duct dilatation [5, $6,8,10]$.

Multimodality imaging techniques are commonly utilized including computed tomography (CT), magnetic resonance imaging (MRI), and/or endoscopic retrograde cholangiopancreatography (ERCP) to confirm the extent of ductal involvement or the presence of extrahepatic disease. A cyst, presenting in the porta hepatitis, separated from the gallbladder and continuing with enlarged biliary ducts can be shown by ultrasound (US) [6].

Upon performing ultrasound at 21 days of age, extrahepatic dilation to form a saccus in the proximal CBD was found, that conforms with type $1 \mathrm{C}$ choledochal cyst.
Prenatal ultrasonography is now being routinely performed worldwide and the detection of choledochal cysts have been reported in fetus. Studies suggest that Type IC cysts are the earliest cysts that can be detected by 15-16 gestational week by fetal ultrasonography. For those who had this condition suspected antenatally, diagnosis is further confirmed after birth by post-natal ultrasound and magnetic resonance cholangiopancreatography and the median gestational age at the initial diagnosis was 20 weeks. Fetal choledochal cyst usually appears as a fluid filled, anechoic mass in the region of the porta hepatis $[6,7,9,13]$.

There have been conflicting arguments in relation to the treatment time of antenatal diagnosed of CCs. Some studies suggest that cases can be operated within 2-6 weeks, even if they are asymptomatic. This is due to potential complication risk of cysts. Other studies, however, suggest that they can be followed-up for a time of period with ultrasound and regular monitoring of liver functions. The definitive treatment for CCs are total excision, which has been suggested being able to fully decrease the risk of malignant degeneration. The general aim is to remove the cyst completely and restore biliary enteric drainage either into the duodenum by hepaticoduodenostomy (HD) or jejunum by Roux-en-Y hepaticojejunostomy (RYHJ), although varying approaches for different types of CCs may be very slightly dissimilar [6, 11-15].

Patient underwent cyst exicion and hepatoduodenostomy at 1 month old. Upon undergoing the procedures, there was no complication observed and the patient was discharged after the seventh day of observation post-surgery. Long term complication of cholangitis was discovered in the patient, 4 months after the surgery. The patient then treated for seven days and prescribed with antibiotic. Upon treatment, the patient has fully recovered from the symptoms.

\section{Conclusion}

Type I choledochal cysts can be identified prenatally during a detailed fetal sonogram. The newborn should be investigated to confirm the diagnosis and undergo cyst excision promptly to reduce the potential for complications. In this particular case, choledochal cysts was discovered since prenatal, which in turn causing a worse prognosis and outlook for the patient. Long term symptoms, in this particular case being cholangitis, can be treated with antibiotics but studies suggest that these symptoms may reappear in the future.

\section{Conflict of Interest}

All the authors do not have any possible conflicts of interest.

\section{Acknowledgements}

The first author would like to acknowledge Supervisors for direction and proper guidance in this case report. 


\section{References}

[1] García NA, Hinojosa AS, Pardo NG, et al. Prenatal diagnosis of a giant choledochal cyst. J Ped Surg Case Reports. 2016; 4: $1-3$.

[2] Eijnden MH, Kleine RH, Blaauw ID, Peeters PG, et al. Choledochal Malformation in Children: Lessons Learned from a Dutch National Study. World J Surg. 2017; 41: 2631-2637.

[3] Soares KC, Goldstein SD, Ghaseb MA, Kamel I, Hackam DJ, Pawlik TM. Pediatric choledochal cysts: diagnosis and current management. Pediatr Surg Int 2017; 33: 637-650.

[4] Soares KC, Arnaoutakis DJ, Kamel I, et al. Choledochal Cysts: Presentation, Clinical Differentiation, and Management. $J \mathrm{Am}$ Coll Surg. 2014; 219 (6): 1167-180.

[5] Singham J, Yoshida EM, Scudamore CH. Choledochal cysts Part 1 of 3: Classification and pathogenesis. J can chir. 2009; 52 (5): $440-434$.

[6] Gezer HO. Pediatric choledochal cysts: unknowns are decreasing. Intech open. (Acces at $30^{\text {th }}$ August 2020). Available at: http//dx.doi.org/10.5772/intechopen.84301.

[7] Foo DC, Wong KK, Lan LC, et al. Impact of prenatal diagnosis on choledochal cysts benefits of early excision. Journal of Paediatrics and Child Health. 2009; 45: 28-30.

[8] Cannella R, Giambelluca D, Diamarco M, Caruana G, Cutaia G, Midiri M, et al. Congenital Cystic Lesions of the Bile Ducts:

imaging-based diagnosis. Current problems in diagnostic radiology. 2019; 49 (4): 285-293.

[9] Lee IH, Kim GJ. Fetal Choledochal Cyst Diagnosed at 22 Weeks of Gestation by Three-Dimensional Ultrasonography: A Case Report. J Korean Med Sci. 2008; 23: 909-11.

[10] Reza M, Nesa NM, Putra IGNS, et al. ype IC Choledochal Cyst Presenting An Extrahepatal Cholestasis In A 3 Year Old Boy. MEDICINA. 2015; 4 (1): 60-56.

[11] Guzman JP, Resurreccion LL, Suntay ML, et al. Comparison between hepaticojejunostomy and hepaticoduodenostomy after excision of choledochal cyst in children: a cohort study. World Jnl Ped Surgery. 2019; 2: e000029.

[12] Buyukyavuz Y, Ekinci S, Ciftci AO, et al. A retrospective study of choledochal cyst: clinical presentation, diagnosis and treatment. The Turkish Journal of Pediatrics. 2003; 45: 321-325.

[13] Mackenzie TC, Howell LJ, Flake AW, et al. The Management of Prenatally Diagnosed Choledochal Cysts. J Pediatr Surg. 2001; 36: 1241-1243.

[14] Cochran ED, Lazow SP, Kim AG, et al. The In-Utero Diagnosis Of Choledochal Cyst: Can Postnatal Imaging Predict Benefit From Early Surgical Intervention? The Journal of Maternal-Fetal \& Neonatal Medicine. 2019; 1: 1-5.

[15] Baez HS, Ramírez PC, Ixtabal EM, et al. Treatment of choledochal cyst in a pediatric population. A single institution experience of 15-years. Case series. Annals of Medicine and Surgery. 2016; 5: 81-85. 